\section{Effects of Citric Acid, Sucrose, and Proton Concentration in Suppressing Defoliation in Hibiscus Plants Grown under Low-illumination Conditions}

\author{
L. Zhang ${ }^{1,2}$, J.R. Livingstone ${ }^{1,3}$, Y. Tarui ${ }^{1,4}$, and E. Hirasawa ${ }^{1,5,6}$
}

ADDITIONAL INDEX WORDs. $\mathrm{pH}$, postharvest, Hibiscus rosa-sinensis

Summary. Potted young hibiscus (Hibiscus rosa-sinensis 'Italian Red') plants were placed in a postharvest environment under low-illumination conditions in a room from 22 July to $31 \mathrm{Dec} .2003$. On treatment with a mineral nutrition (MN) solution, 19\% of their leaves remained intact after 8 weeks, but all the leaves were lost after 12 weeks from the time of placement. Incorporation of citric acid (CA) into the MN solution at a final concentration of $5 \mathrm{mM}$ considerably suppressed the defoliation so that $57 \%$ of the leaves remained intact after 8 weeks and $53 \%$ did so after 12 weeks from the time of placement. Furthermore, treatment with $3 \%$ sucrose (SUC) instead of CA also considerably suppressed the defoliation, with $26 \%$ of the leaves remaining intact for more than 8 weeks and 20\% remaining intact for more than 12 weeks. Neither the CA nor the SUC solution was effective in maintaining the hibiscus plants for more than 20 weeks under low illumination. However, treatment with $\mathrm{MN}$ solution containing CA and SUC was highly effective in suppressing defoliation. About $60 \%$ of the leaves on the plants that were treated with the solution were retained for the entire 24 -week period. The proton concentration of the organic solution was found to be a critical factor that affected plant maintenance. The plants survived only on treatment with a solution of $\mathrm{pH}$ 5.0 , but not with one with a $\mathrm{pH}$ of 6.0 or 7.0 .

$\mathrm{I}$ rradiance plays a major role in the growth and development of plants. Depending on their irradiance requirements, plants can be classified into those that require complete shade, partial shade, and complete irradiance. Plants grow well in natural environments, but it is a considerably challenging endeavor to artificially create favorable and compatible growing conditions for plants. Moreover, the presence of plants at the workplace improves the mood of the office staff by relieving stress, in addition to rendering the office environment more pleasant and attractive (Larsen et al., 1998).

Many types of plants can be grown indoors, but they need to be occasionally placed in bright irradiance for a few hours. For these plants, artificial light in the room-for example, the light emitted by a fluorescent

${ }^{1}$ Department of Biology and Geology, Graduate

School of Science, Osaka City University, Sumiyoshi-ku, Osaka 558-8585, Japan

${ }^{2}$ Graduate Student.

${ }^{3}$ Graduate Researcher.

${ }^{4}$ Instructor.

${ }^{5}$ Professor.

${ }^{6}$ Corresponding author.

E-mail: hirasawa@sci.osaka-cu.ac.jp. lamp-cannot serve as an absolute substitute for high light intensities. The main aim of this study was to establish a method by which plants that require bright sunshine can be maintained in environments supplied with only artificial light, preferably within buildings.

In this study, we examined the effect of injecting exogenous sucrose (SUC) as a carbon nutrient on the suppressing of defoliation, because $3 \%$ SUC is usually added in the medium for plant tissue culture (Mantell et al., 1985). SUC is absolutely necessary for the growth of tissues, which absorb SUC as carbon and energy sources instead of using light to fix carbon dioxide to form carbohydrates. A recent report has shown that infusion of exogenous rose (Rosa hybrida) flower longevity (Monteiro et al., 2002). However, SUC increased attached miniature another issue is that the SUC medium might favor the growth of fungi and other microorganisms. It is also known that citric acid (CA) exhibited antifungal activity in stored fibroin gel (Ayub et al., 1993). Therefore, we examined the postharvest effect of adding CA to the medium. For preparation of the vase solution of cut flowers, the $\mathrm{pH}$ was adjusted with $\mathrm{CA}$, and 8-hydroxyquinoline citrate was used as the antibacterial reagent (Bosma and Dole, 2002), but to our knowledge, there are no reports on the injection of exogenous $\mathrm{CA}$ in potted plants for maintenance in the postharvest environment.

Reid et al. (2002) showed that hibiscus plants have very high light compensation points, therefore we chose this species to determine the possibility of indoor display. However, in the present study, hibiscus was selected as a model species because it requires abundant sunshine and, thus, is a good model for experiments performed with artificial illumination.

\section{Materials and methods}

'Italian Red' hibiscus plants were purchased from J Flowers (Shinsaibashi, Osaka, Japan). They were maintained indoors from 22 July to 31 Dec. 2003 in a room lacking cooling or heating systems at the topmost floor of our four-story school building. The light intensity emitted by fluorescent lamps (FL40S-PG; Panasonic, Osaka, Japan) was maintained at a photon flux density of 4.5 $\mu \mathrm{mol} \cdot \mathrm{m}^{-2} \cdot \mathrm{s}^{-1}$, and was directly incident on the plants. Light was supplied over a diurnal cycle on weekdays, while the room was in darkness at night and on weekends. For all the experiments, three plants that grew in a pot for up to a height of $0.3 \mathrm{~m}$ were used in each treatment unit. The maximum and minimum temperatures in the room were automatically measured with an electric thermometer (Sato Keiki, Tokyo) every week, and the average temperature in the

\begin{tabular}{llll}
\hline $\begin{array}{l}\text { Units } \\
\text { To convert U.S. to SI, } \\
\text { multiply by }\end{array}$ & U.S. unit & SI unit & $\begin{array}{l}\text { To convert SI to U.S., } \\
\text { multiply by }\end{array}$ \\
\hline 29.5735 & $\mathrm{fl} \mathrm{oz}$ & $\mathrm{mL}$ & $\mathbf{0 . 0 3 3 8}$ \\
0.3048 & $\mathrm{ft}$ & $\mathrm{M}$ & 3.2808 \\
2.54 & inch $(\mathrm{es})$ & $\mathrm{cm}$ & $\mathbf{0 . 3 9 3 7}$ \\
$\left({ }^{\circ} \mathrm{F}-\mathbf{3 2}\right) \div 1.8$ & ${ }^{\circ} \mathrm{F}$ & ${ }^{\circ} \mathrm{C}$ & $\left(1.8 \times{ }^{\circ} \mathrm{C}\right)+32$
\end{tabular}

Horthednolng $:$ April-June 2009 19(2) 
room was calculated from these values during each week. The 24-week study period was divided into six 4-week periods, and the average temperatures in the room during the first, second, third, fifth, and sixth periods were $25.2,23.5,18.1,12.2$, and $10.5{ }^{\circ} \mathrm{C}$, respectively.

The hibiscus plants growing in pots were watered once every 2 weeks with $250 \mathrm{~mL}$ of mineral nutrition solution (Nakayama and Hashimoto, 1973). The composition of the mineral nutrition $(\mathrm{MN})$ solution was as follows: $0.62 \mathrm{~mm}$ ammonium nitrate, $0.99 \mathrm{~mm}$ potassium nitrate, $1.06 \mathrm{~mm}$ calcium nitrate, $2.17 \mathrm{~mm}$ ammonium dihydrogenphosphate, $1.02 \mathrm{~mm}$ magnesium sulfate, $6.7 \mu \mathrm{M}$ ferric citrate, $6.6 \mu \mathrm{M}$ manganese sulfate, $3.2 \mu \mathrm{M}$ boric acid, $0.7 \mu \mathrm{M}$ zinc sulfate, $0.08 \mu \mathrm{M}$ copper sulfate, and $0.08 \mu \mathrm{M}$ sodium molybdenum oxide. The $\mathrm{pH}$ of the solution was adjusted to 5.5 with $1 \mathrm{~N}$ potassium hydroxide. Water containing the MN solution was applied once every 2 weeks on Mondays. The other supply with an amended solution containing SUC and/or CA was applied once every 2 weeks on the other Mondays. The amended solution consisted of $\mathrm{MN}$ solution containing or lacking $1 \%$ to $4 \%$ SUC and/or supplemented with 1 to $50 \mathrm{~mm}$ CA. Two-hundred fifty milliliters of the solution was applied to each pot $(15 \mathrm{~cm}$ diameter, $15 \mathrm{~cm}$ height). All of the treatments were initiated simultaneously from 22 July 2003. The loss of leaves in each plant was monitored every 4 weeks, and the average number of leaves remaining among three plants was calculated as a percentage. Data are presented as means \pm SD. Statistical analyses were performed using the Student's two-tailed heteroscedastic $t$ test, and differences were considered to be significant at $P<0.05$.

\section{Results and discussion}

The 24-week study period from 22 July to 31 Dec. 2003 was divided into six 4-week periods. The effects of CA present in the MN on the maintenance of the hibiscus leaves are shown in Fig. 1. The plants that were supplied 1 and $5 \mathrm{~mm}$ CA retained 60\% of their leaves for more than 8 weeks under the low-illumination conditions. This shows that CA was crucial for maintenance of the plants. Furthermore, the plants treated with $5 \mathrm{~mm}$ CA retained up to $40 \%$ of their leaves for more than 16 weeks, while those treated with $1 \mathrm{~mm}$ CA lost all their leaves by this time. However, even the plants that were treated with $5 \mathrm{~mm} C A$ did not survive after 20 weeks under the low-illumination conditions. In contrast, treatment with acetic acid instead of CA completely failed to suppress defoliation of the plant (data not shown).

The amount of SUC supplied with $\mathrm{MN}$ also plays a role in the maintenance of hibiscus leaves. As shown in Fig. 2, $\approx 30 \%$ of the leaves in two of three plants remained intact following treatment with 3\% SUC in MN for 12 weeks, while all the leaves were lost in the plants that were treated with $\mathrm{MN}$ alone during the same time period (Fig. 1). In contrast, defoliation was drastically suppressed when the plants were treated with $\mathrm{MN}$ containing CA and SUC. In particular, $26 \%$ of the leaves of the plants treated with $1 \mathrm{~mm} \mathrm{CA}+$ SUC and $60 \%$ of the leaves of those treated with $5 \mathrm{~mm} \mathrm{CA}+$ SUC remained intact after the 24 week study period (Fig. 2). In contrast, the plants treated with CA at concentrations of more than $5 \mathrm{~mm}$, as well as those treated with $\mathrm{MN}$ alone (Fig. 1), rapidly lost their leaves after 12 weeks, as shown in Fig. 2. These results indicate that an optimal $\mathrm{CA}$ concentration (i.e., between 5 and 10 $\mathrm{mM}$ ) is required for leaf maintenance in hibiscus plants. Hibiscus plants with the best solution lost $32 \%$ of their leaves during the first 8 weeks in summer; they then lost another $8 \%$ of their leaves during the next 16 weeks (i.e., in fall and winter). In environments where the temperature is not controlled, the conditions may be harsh for plants in summer, and the storage conditions may be good during fall and winter because of the respiratory carbon demand.

Fungi were observed on the soil surface in the pots that were watered with MN solutions containing SUC and lacking CA but not in those that were watered with solutions containing CA (data not shown).

By treating the plants with various concentrations of SUC in $\mathrm{MN}$ solution containing $1 \mathrm{~mm} \mathrm{CA}$, we determined the critical concentrations of SUC and CA, which should be used to obtain positive results. As shown in Fig. 3, treatment with $1 \%$ or $4 \%$ SUC had greater effects on defoliation than that with $0 \%$ SUC in $\mathrm{MN}$

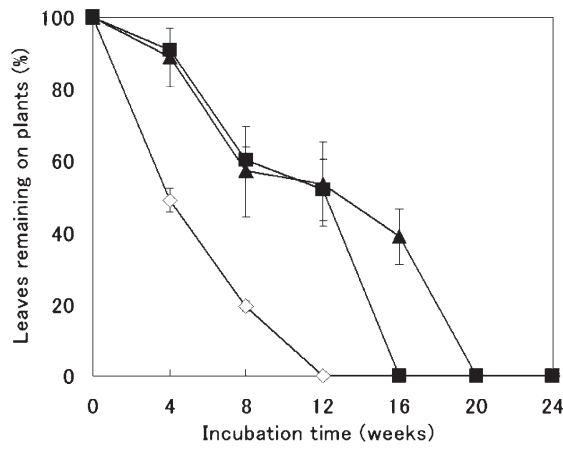

Fig. 1. Effects of citric acid in mineral nutrition on defoliation in hibiscus plants $[\diamond=$ mineral nutrition $(\mathrm{MN})$, $=\mathrm{MN}+1 \mathrm{~mm}$ citric acid (CA), $\Delta=\mathrm{MN}$ $+5 \mathrm{~mm} \mathrm{CA}]$. The loss of leaves in each plant was monitored every 4 weeks, and the average number of leaves remaining among the three plants was calculated as a percentage. Error bars indicate \pm SD. The differences were determined by the Student's two-tailed heteroscedastic $t$ test; " $a$ " and " $b$ " indicate that the values are different from those obtained with $\mathrm{MN}$ at $P<$ 0.01 and $P<0.05$, respectively.

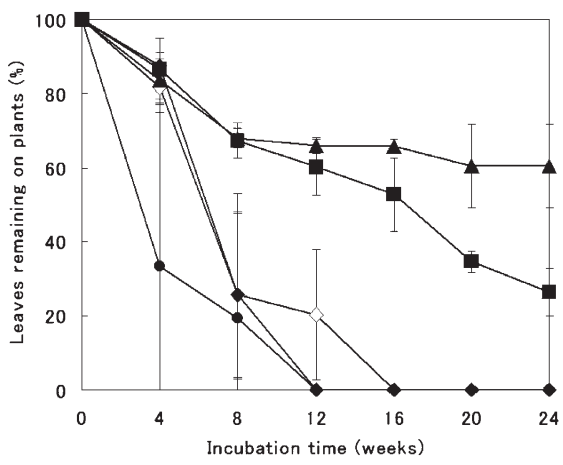

Fig. 2. Effects of citric acid in mineral nutrition containing sucrose on defoliation in hibiscus plants $[\diamond=$ mineral nutrition $(\mathrm{MN})+3 \%$ sucrose (SUC), $=\mathrm{MN}+1 \mathrm{mM}$ citric acid (CA) $+3 \%$ SUC, $\Delta=\mathrm{MN}+5 \mathrm{mM} \mathrm{CA}+\mathbf{3} \%$ SUC, $\bullet=\mathrm{MN}+10 \mathrm{~mm}$ CA $+3 \%$ SUC] The loss of leaves in each plant was monitored every 4 weeks, and the average number of leaves remaining among the three plants was calculated as a percentage. Error bars indicate \pm SD. The differences were determined by the Student's two-tailed heteroscedastic $t$ test; "a" and " $b$ " indicate that the values are different from those obtained with $\mathrm{MN}+3 \%$ SUC at $P<0.01$ and $P<0.05$, respectively.

containing CA. In two of three plants, $20 \%$ to $30 \%$ of the leaves remained intact for more than 8 weeks when treated with $1 \%$ or $4 \%$ SUC in $\mathrm{MN}$ 


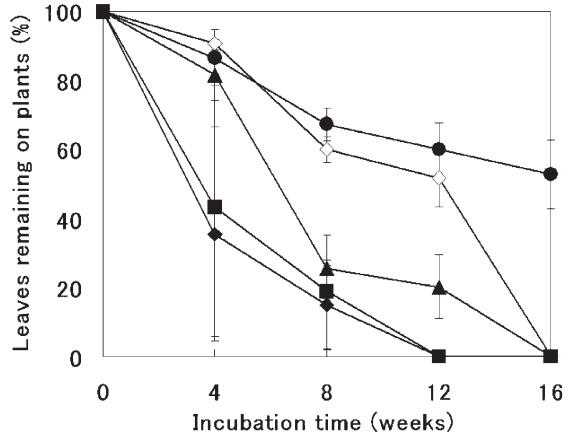

Fig. 3. Effects of sucrose in mineral nutrition containing citric acid on defoliation in hibiscus plants $[\diamond=$ mineral nutrition $(\mathrm{MN})+1 \mathrm{mM}$ citric $\operatorname{acid}(\mathrm{CA}),=\mathrm{MN}+1 \mathrm{mMCA}+1 \%$ sucrose (SUC), $\Delta=\mathbf{M N}+1 \mathrm{mM} C A+$ $2 \% \mathrm{SUC}, \bullet=\mathrm{MN}+1 \mathrm{mMCA}+3 \% \mathrm{SUC}$, $\checkmark \mathrm{MN}+1 \mathrm{~mm} \mathrm{CA}+4 \%$ SUC]. The loss of leaves in each plant was monitored every 4 weeks, and the average number of leaves remaining among the three plants was calculated as a percentage. Error bars indicate \pm SD. The differences were determined by the Student's two-tailed heteroscedastic $t$ test; "a" and " $b$ " indicate that the values are different from those obtained with $\mathrm{MN}+1 \mathrm{~mm} \mathrm{CA}$ at $P<$ 0.01 and $P<0.05$, respectively.

containing CA, while $60 \%$ to $70 \%$ of the leaves remained intact in plants that were treated with $2 \%$ or $3 \%$ SUC. On treatment with $1 \%, 2 \%, 3 \%$, and $4 \%$ SUC in MN containing CA, $0 \%$, $30 \%, 60 \%$, and $0 \%$ of the plant leaves, respectively, remained intact for more than 12 weeks. Thus, the optimal SUC concentration probably lies between $2 \%$ and $3 \%$, but is closer to $3 \%$. The solution containing SUC and CA may attract ants (Formicidae) and other pests in indoor environments. The CA solution without sugar could be commercially manufactured for consumers who are lovers of potted indoor plants.

The effects of the $\mathrm{pH}$ of the organic $\mathrm{MN}$ solution on the maintenance of hibiscus plants grown under low-illumination conditions are shown in Fig. 4. The plants were able to retain a greater number of leaves for more than 4 weeks when treated with $\mathrm{MN}$ at $\mathrm{pH}$ values of 6 and 7 than when treated with that at $\mathrm{pH} 5$. However, after 12 weeks, the plants treated with $\mathrm{MN}$ at $\mathrm{pH}$ values of 6 and 7 began to lose more leaves than those treated with $\mathrm{MN}$ at $\mathrm{pH} 5$. Furthermore, the former plants remained green only for
12 weeks, while the latter plants retained $65 \%$ of their leaves for more than 24 weeks (Fig. 5). Thus, in addition to the CA and SUC concentrations, the proton concentration in the organic MN solution may also be critical for obtaining positive results (i.e., the $\mathrm{pH}$ should be 5.0 , not 6.0 or 7.0). None of the plants that were grown in the room and had lost all their leaves produced new leaves when they were subsequently grown outdoors; however, the plants that were treated with the ideal organic solution and survived produced some small leaves and flower buds when grown outdoors (data not shown).

From the data shown in Fig. 2, which was obtained for plants treated with $\mathrm{MN}$ supplemented with 3\% SUC and contained or lacked CA, it appears that CA is the most important element in the nutrient medium for the maintenance of hibiscus plants under lowillumination conditions. There have been reports on the use of CA to increase the vase life of cut flowers, but this is the first report on its use in intact plants. Pretreatment of canterbury bells (Campanula medium) stems for $4 \mathrm{~h}$ with a floral solution containing deionized water, whose $\mathrm{pH}$ was adjusted to 3.5 with $\mathrm{CA}$ and 8 -hydroxyquinoline citrate, was reported to increase the vase life of cut flowers (Bosma and Dole, 2002). CA may exert a vital effect on plants through its involvement in the tricarboxylic acid cycle, which produces energy in the form of adenosine triphosphate. Furthermore, CA is known to inhibit mycelial growth of the fungi Helminthosporium oryzae and Pyricularia oryzae, which caused grain discoloration in rice (Oryza sativa), and also that of Sarocladium oryzae, which was involved in the sheath rot disease of rice (Narasimhan et al., 1998; Rajappan et al., 2001). Plants secreted organic acids such as $\mathrm{CA}$, malic acid, and oxalic acid from their roots when subjected to abiotic stresses, particularly during exposure to elevated aluminium concentrations or under phosphorus-deficient conditions ( $\mathrm{Ma}$ and Furukawa, 2003; Nian et al., 2003). Apart from inhibiting the growth of microorganisms, CA may protect hibiscus plants from various biotic and abiotic stresses and, when cultured indoors, from toxic minerals in the acidic medium in pots.

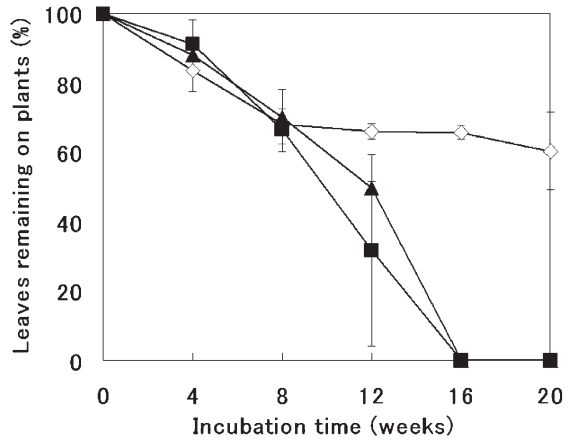

Fig. 4. Effects of $\mathrm{pH}$ in mineral nutrition on defoliation in hibiscus plants $[\diamond=$ mineral nutrition $(\mathrm{MN})+\mathbf{5}$ mM citric acid (CA) $+3 \%$ sucrose (SUC) $(\mathrm{pH} \mathrm{5.0}), \quad=\mathrm{MN}+5 \mathrm{~mm} \mathrm{CA}+3 \% \mathrm{SUC}$ $(\mathrm{pH}$ 6.0), $\Delta=\mathrm{MN}+5 \mathrm{~mm} \mathrm{CA}+\mathbf{3} \%$ SUC (pH 7.0)]. The loss of leaves in each plant was monitored every 4 weeks, and the average number of leaves remaining among the three plants was calculated as a percentage. Error bars indicate \pm SD. The differences were determined by the Student's two-tailed heteroscedastic $t$ test; " $a$ " and " $b$ " indicate that the values are different from those obtained with $\mathrm{MN}+5 \mathrm{~mm} \mathrm{CA}+3 \%$ SUC ( $\mathrm{pH}$ 5.0) at $P<0.01$ and $P<0.05$, respectively.

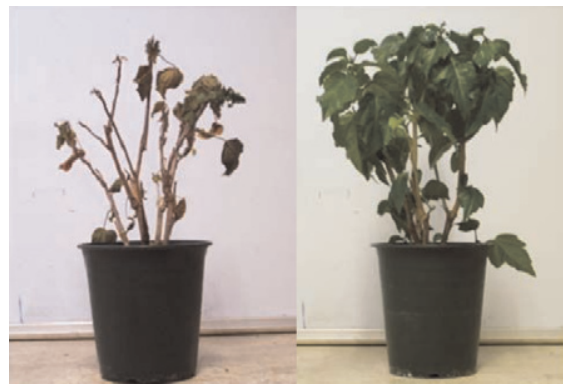

Fig. 5. Comparison between only mineral nutrition and mineral nutrition containing citric acid and sucrose on defoliation in hibiscus plants. The figure on the left shows the plant grown for 10 weeks with only mineral nutrition ( $\mathrm{pH}$ 5.0). The figure on the right shows a plant grown for 28 weeks with mineral nutrition $(\mathrm{pH}$ 5.0) containing $5 \mathrm{~mm}$ citric acid $+\mathbf{3} \%$ sucrose.

From the results of the treatment with various SUC concentrations in MN containing CA (Fig. 2), a critical concentration between $2 \%$ and $3 \%$ and probably closer to $3 \%$ appears to be most effective for suppressing defoliation in plants. The injection of SUC into soybean (Glycine max) plants increased the leaf area and 
number of pods and had an overall positive effect on plant growth, but it was observed to suppress photosynthesis while the plants were being treated with high levels of the photosynthetic end product, SUC (Abdin et al., 1998). SUC is also known to regulate amino acid biosynthesis and to increase the rate of nitrate assimilation and 2-oxoglutarate synthesis (Morcuende et al., 1998; RoessnerTunali et al., 2003). Compared with treatment with $\mathrm{CA}$ alone, treatment with SUC in combination with CA may produce higher levels of energy in the form of adenosine triphosphate. The results of our study show that an alternative carbon source in the form of SUC and an organic acid in the form of CA are required for leaf maintenance in plants grown under low-illumination conditions.

In the present study, treatment with a combination of $5 \mathrm{~mm} C A$ and $3 \%$ SUC at pH 5.0 but not at pH 6.0 or 7.0 was observed to be ideal for the maintenance of hibiscus plants grown under low-illumination conditions (Fig. 4). In the experiments shown in Fig. 4, a higher proton concentration (i.e., a $\mathrm{pH}$ of less than 5 ) was not examined because toxic mineral ions such as $\mathrm{Al}^{3+}$ are soluble in soil at a low $\mathrm{pH}$ (Epstein and Bloom, 2005). The better maintainability of the plant leaves that was observed at $\mathrm{pH} 5.0$ rather than $\mathrm{pH} 6.0$ or 7.0 may be explained by the fact that the growth of phytopathogens is inhibited in acidic soil.

The plants in our study, which were grown indoors from 22 July 2003 to 31 Dec. 2004, were able to withstand not only the hot summer conditions but also the harsh winter conditions, when the temperature of the room was maintained below $10^{\circ} \mathrm{C}$. Plants are known to exhibit reduced SUC synthesis and photosynthesis at low temperatures (Stitt and Hurry,
2002). However, the hibiscus plants in our study retained their leaves and green color even at low temperatures. These results suggest that plants can be grown indoors; however, the physiological aspects that influence their maintenance remain to be explored. We are currently investigating methods to establish the physiological and biochemical bases of the indoor growth of various plants following treatment with various concentrations of SUC and CA.

\section{Literature cited}

Abdin, O.A., X. Zhou, B.E. Coulman, D. Cloutier, M.A. Faris, and D.L. Smith. 1998. Effect of sucrose supplementation by stem injection on the development of soybean plants. J. Expt. Bot. 49:20132018.

Ayub, Z.H., M. Arai, and K. Hirabayashi. 1993. Relation between $\mathrm{pH}$ and development of fungi in stored fibroin gel. Nippon Sanshigaku Zasshi 62:325-328.

Bosma, T. and J.M. Dole. 2002. Postharvest handling of cut Campanula medium flowers. HortScience 37:954958.

Epstein, E. and A.L. Bloom. 2005. Mineral nutrition of plants: Principle and perspectives, 2nd ed. Sinauer Assoc., Sunderland, MA.

Larsen, L., J. Adams, B. Deal, B.S. Kweon, and E. Tyler. 1998. Plants in the workplace. The effects of plant density on productivity, attitudes and perceptions. Environ. Behav. 30:261-281.

Ma, J.F. and J. Furukawa. 2003. Recent progress in the research of external $\mathrm{Al}$ detoxification in higher plants: A minireview. J. Inorg. Biochem. 97:46-51.

Mantell, S.H., J.A. Matthews, and R.A. Mckee. 1985. Principle of plant biotechnology. Blackwell Scientific, Oxford, UK.

Monteiro, J.A., T.A. Nell, and J.E. Barrett. 2002. Effects of exogenous sucrose on carbohydrate levels, flower respiration and longevity of potted miniature rose flowers during postproduction. Postharvest Biol. Technol. 26:221-229.

Morcuende, R., A. Krapp, V. Hurry, and M. Stitt. 1998. Sucrose-feeding leads to increased rates of nitrate assimilation, increased rates of $\alpha$-oxoglutarate synthesis, and increased synthesis of a wide spectrum of amino acids in tobacco leaves. Planta 206:394-409.

Nakayama, S. and T. Hashimoto. 1973. Effect of abscisic acid on flowering in Pharbitis nil. Plant Cell Physiol. 14:419-422.

Narasimhan, V., K. Rajappan, C. Ushamalini, and A.A. Kareem. 1998. Efficacy of new formulations of neem oil and pungam oil for the management of sheath rot disease of rice. Phytoparasitica 26:301-306.

Nian, H., S.J. Ahn, Z.M. Yang, and H. Matsumoto. 2003. Effect of phosphorus deficiency on aluminium-induced citrate exudation in soybean (Glycine max). Physiol. Plant. 117:229-236.

Rajappan, K., C. Ushamalini, N. Subramanian, V. Narasimhan, and A.A. Kareem. 2001. Management of grain discoloration of rice with solvent-free EC formulations of neem and pungam oils. Phytoparasitica 29:171-174.

Reid, M.S., B. Wollenweber, and M. Serek. 2002. Carbon balance and ethylene in the postharvest life of flowering hibiscus. Postharvest Biol. Technol. 25:227233.

Roessner-Tunali, U., E. UrbanczykWochniak, T. Czechowski, A. Kolbe, L. Willmitzer, and A.R. Fernie. 2003. De novo amino acid biosynthesis in potato tubers is regulated by sucrose levels. Plant Physiol. 133:683-692.

Stitt, M. and V. Hurry. 2002. A plant for all seasons: Alterations in photosynthetic carbon metabolism during cold acclimation in Arabidopsis. Curr. Opin. Plant Biol. 5:199-206. 